\title{
Direct and indirect nursing care time in an intensive care unit ${ }^{1}$
}

\author{
Luciana Emi Kakushi² \\ Yolanda Dora Martinez Évora ${ }^{3}$
}

Objective: to identify the direct and indirect nursing care time in an intensive care unit. Method: a descriptive/exploratory study conducted at a private hospital. The Nursing Activities Score classification system was used to estimate the direct care time, and electronic health records were used to estimate the indirect care time. The data were collected from March to June 2011. Results: the findings indicate that the average nursing care time was 29.5 hours, consisting of 27.4 hours of direct care and 2.1 hours of indirect care per patient/day. The nursing care time was higher on weekends and holidays, with predominant use of electronic medical records at night. Conclusion: ascertaining nursing care times will contribute to a quantitative evaluation of human resources, assisting in the determination of workloads and workforce size.

Descriptors: Time and Motion Studies; Nursing Care; Intensive Care Units; Medical Records Systems, Computerized; Workload.

\footnotetext{
${ }^{1}$ Paper extracted from master's thesis "Measurement and analysis of time direct and indirect nursing care in Internsive Care Unit", presented to Escola de Enfermagem de Ribeirão Preto, Universidade de São Paulo, WHO Collaborating Centre for Nursing Research Development, Ribeirão Preto, SP, Brazil.

2 Doctoral Student, Escola de Enfermagem de Ribeirão Preto, Universidade de São Paulo, WHO Collaborating Centre for Nursing Research Development, Ribeirão Preto, SP, Brazil.

${ }^{3}$ PhD, Full Professor, Escola de Enfermagem de Ribeirão Preto, Universidade de São Paulo, WHO Collaborating Centre for Nursing Research Development, Ribeirão Preto, SP, Brazil.
}

Corresponding Author:

Luciana Emi Kakushi

Rua São Salvador, 902

Bairro: Sumarezinho

CEP: 14055-260, Ribeirão Preto, SP, Brasi

E-mail: lucianakakushi@usp.br
Copyright @ 2014 Revista Latino-Americana de Enfermagem This is an Open Access article distributed under the terms of the Creative Commons Attribution Non-Commercial License (CC BY-NC).

This license lets others distribute, remix, tweak, and build upon your work non-commercially, and although their new works must also acknowledge you and be non-commercial, they don't have to license their derivative works on the same terms. 


\section{Introduction}

Measuring the average nursing care time is an objective measure for assessing the quantity and quality of the nursing staff in hospitals because it allows hospitals to evaluate the condition of the existing human resources ${ }^{(1)}$. Thus, in intensive care units (ICU), predictions for personnel requirements should be estimated using instruments that consider the various nursing activities involved, which helps to quantify the actual workload and determine the number of workers needed to form a team ${ }^{(2)}$

In the current context, the instruments for assessing a patient's clinical condition and required care needs have become indispensable in efforts to improve the cost-effectiveness of health care ${ }^{(3)}$. Thus, care indicators are increasingly needed in nursing to ensure the quality of care, helping to quantify the number of staff required to provide care that is safe for both the patients and the health professionals.

Thus, the Nursing Activities Score (NAS) is an instrument that has been designed to measure the actual nursing workload in ICUs, quantifying the nursing care and the degree of complexity involved. The total score obtained using the NAS scoring system represents the percentage of time spent by nurses per shift in direct patient care ${ }^{(3)}$

It is in these scenarios that identifying the nursing workload is key to determining the needed workforce of health professionals. To identify this variable, the time that nurses use to provide patient care must be measured, and the tools used to measure the workload should also consider indirect care activities ${ }^{(4)}$.

According to the Nursing Interventions Classification (NIC), direct care intervention is a treatment performed through interaction with the patient(s), direct social actions and counseling. Indirect care intervention is a treatment performed away from the patient, but on his/ her behalf or on behalf of a group of patients, where these actions support the overall effectiveness of direct care interventions ${ }^{(5)}$

Given that the ICU is one of the health care fields where technology is constantly improving, in addition to a large amount of patient information and data, a significant amount of attention has been directed toward electronic health systems. The use of information technology systems provides easy access to information, data sharing possibilities, simultaneous access to information by multiple professionals, legibility and integration with other health information systems ${ }^{(6)}$, reducing the overall time spent on documenting patient care activities ${ }^{(7-8)}$

The advantages and benefits of an electronic system have been surveyed by several authors ${ }^{(6-8)}$. However, some studies report that there is insufficient evidence regarding the time spent on nursing documentation in electronic systems and its impact on patient care ${ }^{(9-10)}$. The importance of measuring the time spent on nursing documentation and other processes involving electronic health systems has prompted the following research question: how much time is spent by the nursing staff on direct and indirect patient care in the ICU, when using an electronic health system?

Thus, the aim of this study was to identify the direct and indirect nursing care time in an intensive care unit.

\section{Methods}

This project was a descriptive/exploratory study developed in collaboration with the ICU of a private hospital located in Ribeirão Preto, state of São Paulo-SP

The ICU involved in this study serves both children and adults and has 20 beds, four of which are reserved for patients who require some form of isolation.

The theoretical framework of this research was based on the Nursing Interventions Classification (NIC), which defines direct and indirect nursing care interventions and estimates the time required to perform each of these activities.

The study population consisted of the ICU nursing staff, including nine clinical nurses, 27 nursing technicians, 24 nursing assistants and one nurse coordinator. The sample population consisted of eight nurses, 25 nursing technicians and 21 nursing assistants scheduled to work the morning, afternoon and night shifts and who agreed to participate in the study by signing an informed consent form.

The data relating to the direct care time were calculated using the NAS instrument, which quantifies care by scoring nursing activities. The nurses in the studied ICU employed this method daily and retrospectively (past 24 hours) for all the patients in the ICU, as designed and indicated for use. The NAS score was calculated in the form of points and subsequently transformed into time units, for which each point in the NAS score corresponds to 14.4 minutes of direct nursing care $^{(11)}$.

The data regarding the indirect care time were provided by information technology professionals at the institution. In this study, these times were defined as the 
time required to record nursing staff actions in patient care and perform other processes involving electronic health records (EHRs), such as requesting, suspending and returning materials and medications to the pharmacy. These data were obtained via the electronic medical record system, which provided a report consisting of the following information: Username, Log on - day, Log on - Time, Log off - day and Log off - time. This information was used to calculate the time the user spent using the electronic medical records during his/ her work shift.

In total, 25,239 records were obtained for the nursing staff's use of electronic medical records, 355 of which were excluded because the log-off time was not recorded. Therefore, the analysis consisted of 24,884 records.

The time provided by the information technology system was in hours, minutes and seconds (hh:mm:ss). Statistical tools were used to transform the times into decimal places (in minutes), thus allowing the results to be compared with the NAS.

In addition to transforming the values into similar units for comparisons, the statistical treatment also determined the direct care time (NAS) and indirect care time (EHR) in the ICU, the care time per number of patients, the care time per work period [daytime (07:00 to $19: 00$ hours) and nighttime (19:00 to 07:00 hours)] and the care time on weekdays (Monday to Friday) and on weekends and holidays.
Data were collected from March 2011 to June 2011, and the results are presented graphically.

This project was approved by the Research Ethics Committee of the Ribeirão Preto School of Nursing, University of São Paulo [Universidade de São Paulo USP] (protocol No. 1244/2010) and was authorized by the institution under study.

\section{Results}

From March 2011 to June 2011, 477 patients were admitted to the ICU, with an average of 119 patients/ month. During the study period, the occupancy rate remained at an average of $86.7 \%$, making it possible to evaluate the work dynamics of the unit.

The mean age of the patients was 64 years, which can be considered an elderly population. They were predominately male, at $56.5 \%$ (67).

The average ICU stay was 4.4 days, and the older patients remained in the unit for longer periods due to their slower recoveries.

The predominant reasons for admission were clinical at $63.4 \%$ (75) and surgical at 36.5\% (43), which is consistent with the average advanced age of the patients and the patients' health requirements.

The distribution of the professional staff categories of the unit were as follows: $14.8 \%$ nurses, $46.3 \%$ nursing technicians and $38.9 \%$ nursing assistants.

Figure 1 below shows the direct nursing care time (NAS) over the study period.

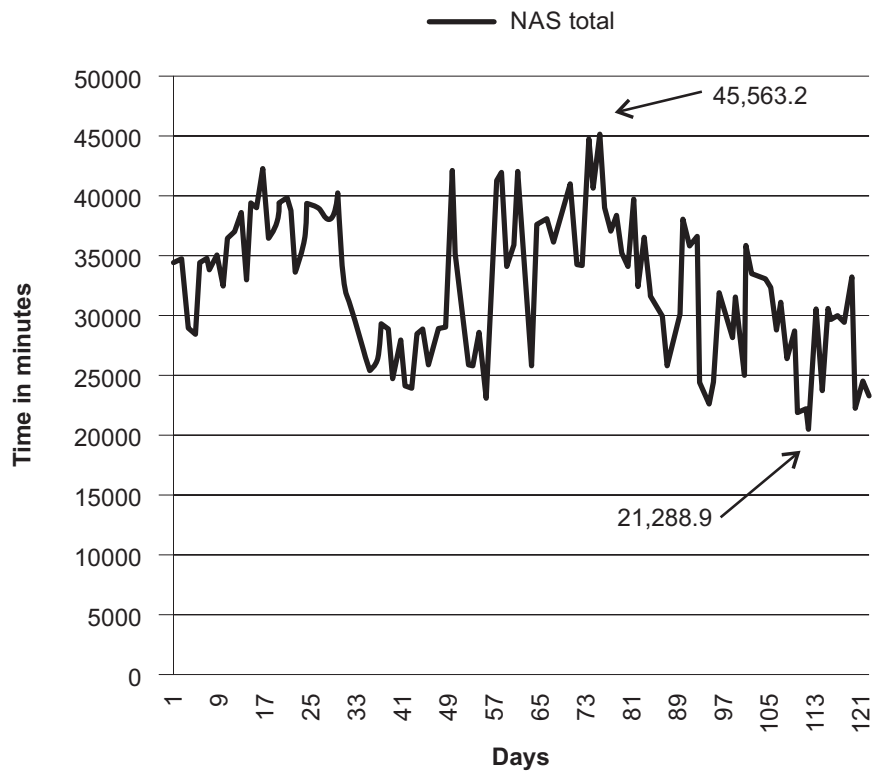

Figure 1 - Distribution of the direct nursing care time (NAS) for the period between March 2011 and June 2011, Ribeirão Preto, SP, Brazil, 2012 
The care times varied over the study period ( $a$ minimum of 21,288.9 minutes and a maximum of 45,563.2 minutes). The average time was 32,391.4 minutes (539.8 hours) per day in the unit, and thus, each patient required an average of $1,649.3$ minutes (27.4 hours) of direct nursing care per day.

The conversion of the NAS score into points, which represents the percentage of nursing time per shift spent in direct patient care, yielded an average of $114.3 \%$ per ICU patient in this study.
Figure 2 below shows the indirect nursing care time (EHR) over the study period.

The distribution of the indirect care time was also not constant (a minimum of 1,221.4 minutes and a maximum of $4,082.0$ minutes). The average was $2,420.1$ minutes ( 40.3 hours) per day in the unit, of which each patient received 126.0 minutes or 2.1 hours of indirect nursing care per day.

Figure 3 shows the distribution of direct and indirect nursing care time (NAS + EHR) over the study period.

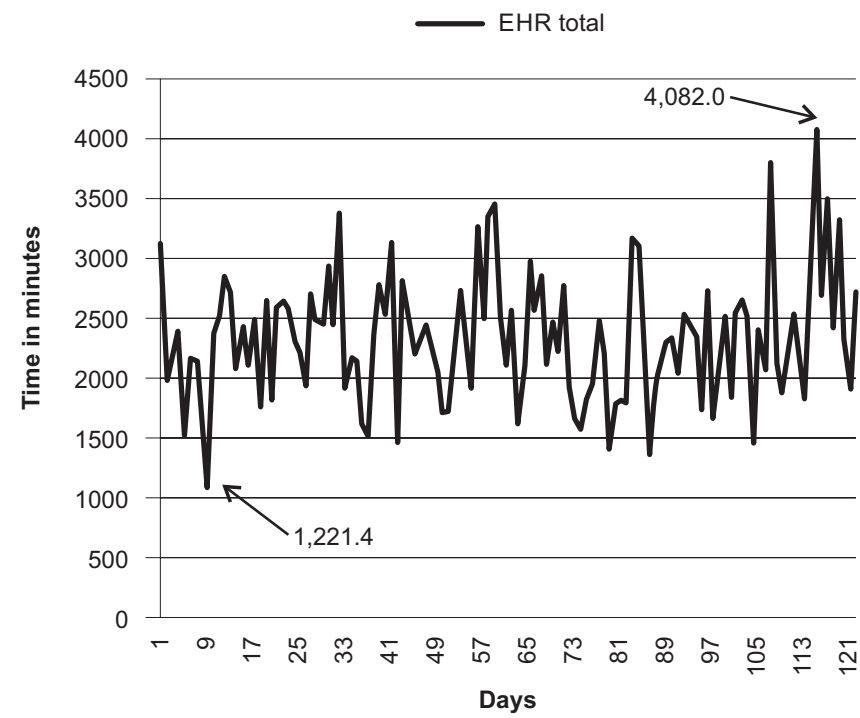

Figure 2 - Distribution of the indirect nursing care time (EHR) for the period between March 2011 and June 2011, Ribeirão Preto, SP, Brazil, 2012

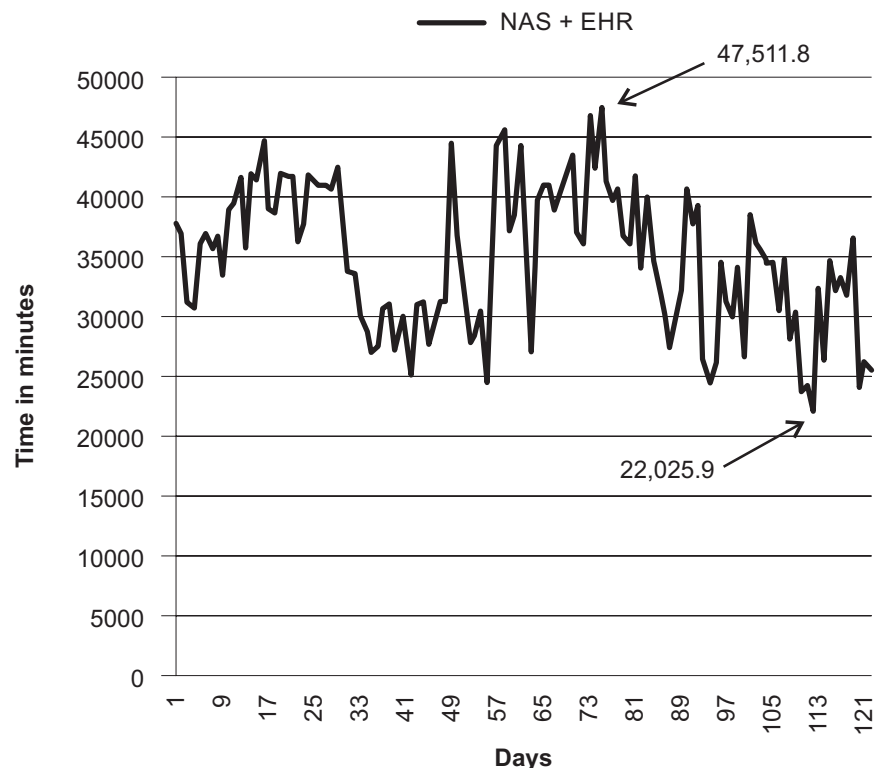

Figure 3 - Distribution of direct and indirect nursing care time (NAS + EHR) for the period between March 2011 and June 2011, Ribeirão Preto, SP, Brazil, 2012 
There is variability in the care time (a minimum of 22,025.9 minutes and a maximum of $47,511.8$ minutes). The average care time was $34,811.5$ minutes (582.7 hours) per day in the unit. Therefore, each patient required an average of $1,774.8$ minutes (29.5 hours) of nursing care per day.
Thus, the nursing care time in the ICU in this study was 29.5 hours per patient/day, 27.4 hours (93\%) of which was for direct care and 2.1 hours (7\%) for indirect care.

Figure 4 below shows the direct and indirect nursing care time analyzed in relation to the days of the week.

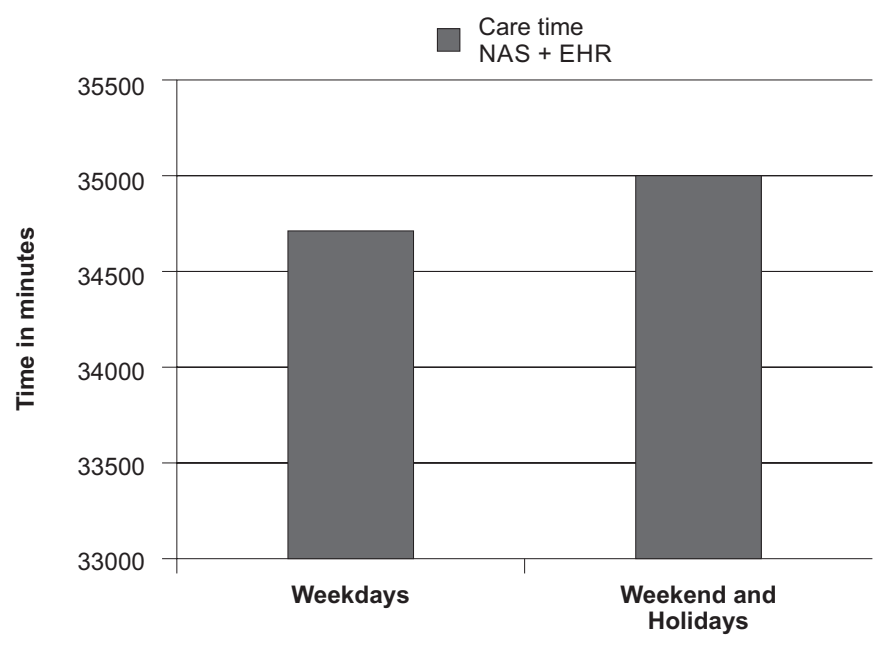

Figure 4 - Distribution of the direct and indirect nursing care time (NAS + EHR) in relation to the days of the week, for the period between March 2011 and June 2011, Ribeirão Preto, SP, Brazil, 2012

Figure 4 shows that the direct and indirect nursing care time is higher on weekends and holidays at $35,009.5$ minutes (583.4 hours), compared to weekdays at 34,728.6 minutes (578.8 hours), i.e., 29.7 hours are required on weekends and holidays and 29.3 hours on weekdays, which is an increase of 24.0 minutes of nursing care per patient/day on weekends and holidays.
Given the distribution of the time spent on EHR during the daytime and nighttime shifts over the study period, shown in Figure 5 below, the nurses spent an average of 878.9 minutes (14.6 hours) during the daytime shift and 1,541.3 minutes (25.6 hours) during the nighttime shift on EHR.

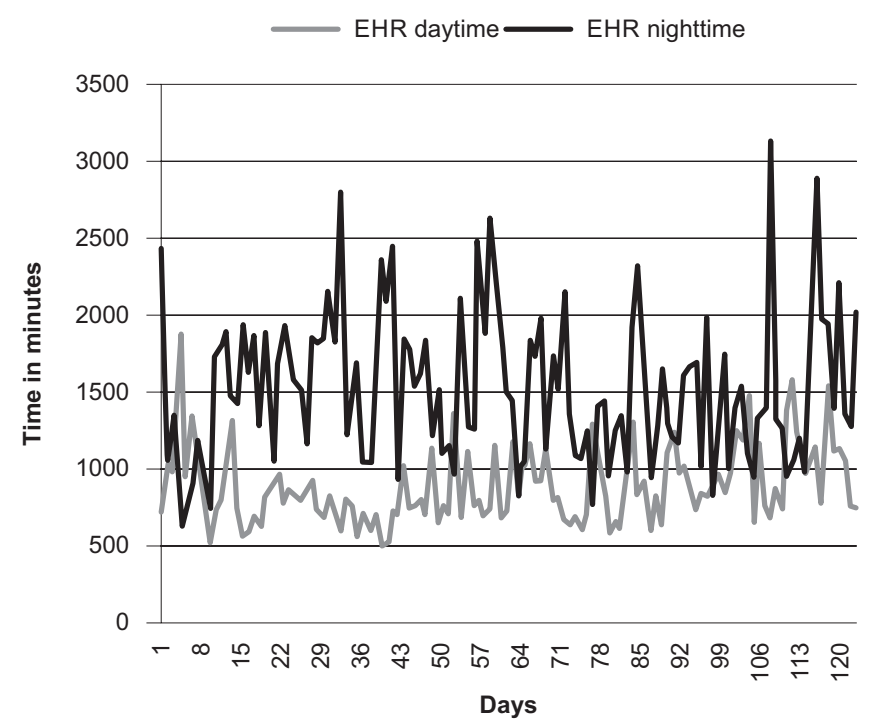

Figure 5 - Distribution of time spent on electronic patient records (EHR) during the daytime and nighttime shifts for the period between March 2011 and June 2011, Ribeirão Preto, SP, Brazil, 2012 
The average time spent on EHR during the daytime shift was 46.0 minutes per patient/day, and during the nighttime it was 79.9 minutes (1.3 hours) per patient/ day, i.e., an increase of 33.9 minutes per patient/day during the nighttime shift.

The distribution of $2.5 \%$ during the daytime shift and $4.3 \%$ during the nighttime shift for the use of electronic medical records combine for a total percentage of indirect care nursing time of $7 \%$.

\section{Discussion}

The daily direct and indirect nursing care time in the ICU in this study was 29.5 hours. Based on the levels established by Resolution No. 293/2004(12) of the Federal Nursing Board (Conselho Federal de Enfermagem - COFEN), the hours of care measured here were higher than the number of hours recommended by the resolution, established at 17.9 nursing hours per client for intensive care.

According to the percent distribution of the number of nurses in the ICU in this study, the number of nurses here was lower than the numbers indicated by the COFEN Resolution No. 293/2004(12). The resolution has established a proportion of $52-56 \%$ for nurses and the remaining percentage for nursing technicians in intensive care units. The National Health Surveillance Agency (Agência Nacional de Vigilância Sanitária -ANVISA) also recommends that the nursing care of patients in the ICU ${ }^{(13)}$ be performed by nurses and nursing technicians. It is important to note that in this unit, the nursing technicians and nursing assistants performed the same nursing activities.

The NAS scores for the unit studied (114.3\%) can be compared to other studies that have reported averages of $80.1 \%{ }^{(14)}, 96.2 \%{ }^{(15)}, 96.7 \%{ }^{(16)}$ for an ICU specializing in cardiac surgery. It is worth noting that the ICU studied here also cares for patients in the immediate postoperative period following cardiac surgery (16\% of admissions), which could explain this increase in the NAS score. Another factor that could account for this increase may be related to the item administrative and managerial tasks, through the application of various protocols for all patients admitted to the unit, including protocols for preventing ventilator-associated pneumonia, preventing pressure ulcers and preventing falls, which together add 23.2 points to the score of nursing activities. It may also be related to the item mobilization and positioning, regarding the daily transfer of patients to another bed within the ICU, which requires three or more nurses to carry out the procedure, increasing the total NAS score by 17.0 points.

The NAS score was not affected by the fact that the unit receives both children and adults, as the determination of the points for the classification instrument is based on the nursing activities performed on the patient.

The time spent on electronic records was 2.1 hours for nursing documentation, i.e., a decrease of 24.0 minutes per patient/day spent on documentation using an electronic record system compared to the time estimated by the NIC classification system ${ }^{(17)}$ (2.5 hours). The time spent on electronic records in the ICU in this study not only accounts for the documentation of nursing activities, but encompasses all processes that involve the use of the electronic systems, such as the activities of requesting, suspending and returning materials and medications, i.e., nursing actions aimed at indirect patient care.

It is important to note that the electronic systems in the unit in this study do not have a time out function, i.e., a safety feature that logs out a user after a few minutes of no activity on the system. Thus, the user can remain logged in without necessarily using the electronic health records.

The percentage of time used for indirect nursing care $(7 \%)$ is consistent with the results of other studies that also used the NIC classification system in measuring the average documentation time and that showed that the time spent on documentation by nursing staff to be $9.6 \%{ }^{(18)}, 9.3 \%^{(19)}$ and $6.74 \%(20)$. However, these studies do not identify the electronic systems used.

The time spent on documentation using electronic health records during the daytime $(2.5 \%)$ and nighttime (4.3\%) shifts differ from each other and also from other studies that reported percentages of $19.2 \%$ for the daytime shift and $12.4 \%$ for the nighttime shift ${ }^{(21)}$ and of $11.3 \%$ in the morning and $6.7 \%$ in the evening ${ }^{(19)}$. This difference in the documentation times between shifts can be explained by the increased number of patients in these units during the daytime shift, which differs from admittance into the ICU. The prevalence of the use of EHR at night can be explained by the increased availability of computers during this period, as these devices are shared with various health professionals who attend to patients during the day.

The nursing care time was higher on weekends and holidays, which is consistent with the results reported by other researchers who have shown that this variation in workload was also observed on different days of the 
week, noting that highest NAS averages were found on Thursdays and Saturdays ${ }^{(22)}$.

\section{Conclusion}

This study enabled the determination of the nursing care time spent on the patients in the ICU studied here, measuring the direct and indirect nursing care time.

To determine the direct care time, the NAS system was used to classify nursing activities, which identified a high workload in the unit due to specific activities being performed. Having identified these activities, the multidisciplinary team will continue to search for ways to improve the care while also reducing the staff's workload, serving the real needs of the patients and eliminating activities that do not add significant value to their care. This study also found a large variation in the workload of the unit, making it difficult to appropriately allocate personnel in such a way as to provide adequate care for the needs of the patients.

Electronic patient records were used to measure the indirect care time by identifying the time spent on an electronic system. This measure can be translated into the time spent on an electronic system, which involves both recording nursing activities and completing other processes related to patient care. However, it can also overestimate the use of the system because users can be logged onto the electronic records while not fully utilizing them. It is therefore important to separately evaluate each module of the system to identify the actual time spent on each process.

From this study, it was also possible to determine that the nursing care time was higher on weekends and holidays, requiring an examination of the intrinsic factors responsible for this increase in care time.

In addition to the data mentioned above, additional aspects of the study should be noted, including the higher prevalence of use of the electronic medical record during the nighttime shift. It is therefore important to examine the differences between shifts, indicating the need to check the contents of the nursing records and determine the relationship between the increased time spent and their content.

Thus, the data found by determining the average nursing care time and by identifying the specific activities in the ICU in this study are important for guiding the decision-making processes regarding the management of the unit, directing the actions of nurses so they can care for patients' health care needs with knowledge, skill, competence and safety.

\section{References}

1. Rogenski KE, Fugulin FMT, Gaidzinski RR, Rogenski NMB. Tempo de assistência de enfermagem em instituição hospitalar de ensino. Rev Esc Enferm USP. [Internet]. 2011. [acesso 13 jun 2012]; 45 (1): 223-9. Disponível em: http://www.scielo.br/scielo.php?pid=S0080-62342011 $000100031 \&$ script $=$ sci_arttext

2. Inoue KC, Matsuda LM. Dimensionamento de pessoal de enfermagem em Unidade de Terapia Intensiva para adultos. Acta Paul Enferm. [Internet]. 2010 [acesso 6 jun 2011], 23(3): 379-84. Disponível em: http://www. scielo.br/scielo.php?script $=$ sci_arttext\&pid $=$ S010321002010000300011\&lng=en\&nrm=iso\&tlng=pt

3. Queijo AF, Padilha KG. Nursing Activities Score (NAS): adaptação transcultural e validação para a língua portuguesa. Rev Esc Enferm USP. [Internet]. 2009 [acesso 11 abril 2011]; 43: 1018-25. Disponível em: http://www.scielo.br/scielo.php?pid=S0080-6234200 9000500004\&script=sci_arttext

4. Abbey M, Chaboyer W, Mitchell M. Understanding the work of intensive care nurses: a time and motion study. Aust Crit Care. 2012;25(1):13-22.

5. Bulechek GM, Butcher HK, Dochterman JM. Definições de termos. In: Bulechek GM, Butcher HK, Dochterman JM. Classificação das Intervenções de Enfermagem (NIC). Rio de Janeiro (RJ): Elsevier; 2010. p. 25-7.

6. Galvão MCB, Ricarte ILM. Informatização. In: Galvão MCB, Ricarte ILM. Prontuário do paciente. Rio de Janeiro (RJ): Guanabara Koogan; 2012. p. 31-54.

7. Hannah KJ, Ball MJ, Edwards MJA. Aplicações na prática clínica baseada em unidade de cuidado. In: Hannah KJ, Ball MJ, Edwards MJA. Introdução à informática em enfermagem. Porto Alegre: ArtMed; 2009. p. 123-36.

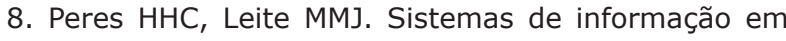
saúde. In: Kurggant P. Gerenciamento em enfermagem. Rio de Janeiro: Guanabara Koogan; 2010. p. 63-70.

9. Madorum RL, Shaw NT. The impact of a critical care information system (CCIS) on time spent charting and in direct patient care by staff in the ICU: a review of the literature. Int J Med Inform. 2009;78 (7):435-45.

10. Ammenwerth E, Rauchegger F, Ehlers F, Hirsch B, Schaubmayr C. Effect of a nursing information system in the quality of information processing in nursing: an evaluation study using the HIS-monitor instrument. Int J Med Inform. 2011;80(1):25-38.

11. Conishi RMY, Gaidzinski RR. Nursing Activities Score (NAS) como instrumento para medir carga de trabalho de enfermagem em UTI adulto. Rev ESC Enferm USP. [Internet]. 2007. [acesso 12 nov 
2011]; 41 (3): 346-54. Disponível em: http://www. scielo.br/scielo.php?script =sci_arttext\&pid=S0080$62342007000300002 \&$ Ing $=$ en\&nrm=iso

12. Conselho Federal de Enfermagem (BR). Resolução no 293, de 21 set 2004. [Internet]. Fixa e Estabelece Parâmetros para Dimensionamento do Quadro de Profissionais de Enfermagem nas Unidades Assistenciais das Instituições de Saúde e Assemelhados. 2004. [acesso 20 ago 2011]. Disponível em: http://pnass. datasus.gov.br/documentos/normas/122.pdf

13. Ministério da Saúde (BR). Agência Nacional de Vigilância Sanitária. RDC no 7, de 24 fev 2010 [Internet]. Dispõe sobre os requisitos mínimos para funcionamento de Unidades de Terapia Intensiva e dá outras providências. 2010. [acesso 20 ago 2011]. Disponível em: http://www. amib.org.br/pdf/RDC-07-2010.pdf

14. Balsanelli AP, Cunha ICKO, Whitaker IY. Nurses' leadership styles in the icu: association with personal and professional profile and workload. Rev. Latino-Am. Enfermagem. 2009;17(1):28-33.

15. Stafseth SK, Solms D, Bredal IS. The characterisation of workloads and nursing staff allocation in intensive care units: a descriptive study using the Nursing Activities Score for the first time in Norway. Intensive Crit Care Nurs. 2011;27(5):290-4.

16. Dias MCCB. Aplicação do Nursing Activities Score - NAS - como instrumento de medida de carga de trabalho de enfermagem em UTI Cirúrgica Cardiológica [dissertação na internet]. São Paulo (SP): Escola de Enfermagem da Universidade de São Paulo; 2006.

17. Bulechek GM, Butcher HK, Dochterman JM. Tempo estimado e nível de formação necessários para a realização das intervenções NIC. In: Bulechek GM, Butcher HK, Dochterman JM. Classificação das Intervenções de Enfermagem. Rio de Janeiro: Elsevier; 2010. p. 799-822.

18. Mello MC. Carga de trabalho de enfermagem: indicadores de tempo em unidades de clínica médica, cirúrgica e terapia intensiva adulto [Internet]. São Paulo (SP): Escola de Enfermagem da Universidade de São Paulo; 2011 [acesso 23 ago 2012]. 228 p. Disponível em: http://www.teses.usp.br/teses/disponiveis/7/7140/tde25082011-095746/pt-br.php

19. Kiekas P, Poulopoulou M, Papahatzi A, Androutsopoulou C, Maliouki M, Prinou A. Nursing activities and use of time in the Postanesthesia care unit. J PeriAnesth Nurs. $2005 ; 20(5): 311-22$.

20. Garcia EA, Fugulin FMT. Distribuição do tempo de trabalho das enfermeiras em unidade de emergência. Rev Esc Enferm USP. [Internet]. 2010 [acesso 9 set
2011]; 44(4):1032-8. Disponível em: http://dx.doi. org/10.1590/S0080-62342010000400025

21. Korst LM, Eusebio-Angeja AC, Chamorro T. Aydin CE, Gregory KD. Nursing documentation time during implementation of an electronic medical Record. JONA. 2003 Jan;33(1):24-30.

22. Novelli e Castro MC, Dell'acqua MC, Corrente JE, Zornoff DCM, Arantes LF. Aplicativo informatizado com o Nursing Activities Score: instrument para gerenciamento da assistência em unidade de terapia intensiva. Texto Contexto-Enferm. [Internet]. 2009. [acesso 12 ago 2012]; 18(3):577-85. Disponível em: http://www.scielo.br/scielo.php?script=sci_arttext\&pid $=$ S0104-0707200900030002
Received: Nov. 29th 2012 Accepted: Sept. 30th 2013 